\title{
A Novel Technique: Conceived Predictive Diagonal (CPD) Graphical Nonlinear Regression Modeling and Simulation
}

\author{
Ebrahim abdelgawad ${ }^{1}$ \\ ${ }^{1}$ Nuclear Materials Authority
}

June 4, 2020

\begin{abstract}
The present work predicts a novel technique for treating workable results. It aims to more professional data analysis with less numbers of experiments. A Predictive Conceived Diagonal (PCD) technique is suggested for this target. For the latter a non-linear regression procedure is applied using MATLAB software. Four published examples are employed and treated. By deploying rate of reaction -Arrhenius combination for studying a pair of factors simultaneously the performed results are very closed to that reported. It also successfully applied for lab scale uranium removal from nitrate solution by Amberlite IR 120 at Nuclear Materials Authority, Egypt.
\end{abstract}

\section{Hosted file}

A Novel Technique Conceived Predictive Diagonal (CPD).doc available at https://authorea. com/users/329969/articles/456840-a-novel-technique-conceived-predictive-diagonal-cpdgraphical-nonlinear-regression-modeling-and-simulation

\section{Hosted file}

Figs.docx available at https://authorea.com/users/329969/articles/456840-a-novel-techniqueconceived-predictive-diagonal-cpd-graphical-nonlinear-regression-modeling-and-simulation 